\title{
Understanding Foreign Exchange Option Returns: The Information Content Of Volatility
}

Lamya Kermiche, Grenoble Ecole de Management, France Philippe Dupuy, Grenoble Ecole de Management, France

\begin{abstract}
According to general asset pricing theory, options should reward their holders for the systematic risk they are bearing. In this paper, we study the returns of foreign exchange options. We find that, by sorting options according to the distance of their implied volatility from the historical volatility, we obtain portfolios with positive average monthly returns. These returns are not explained by standard aggregate risk factors, which suggest either that additional risk factors should be accounted for, or that investors behavior differs from the traditional paradigm of rational agents.
\end{abstract}

Keywords: Asset Pricing Theory; Foreign Exchange Option Returns; Historical and Implied Volatility

\section{INTRODUCTION}

¿ $\mathrm{n}$ the asset pricing theory, all the risky assets are expected to compensate their holders according to the systematic risk they are supposed to bear. Options, like other risky assets, should respect this principle. However, since the development of the derivatives markets, research on options mainly focused on the pricing and hedging aspects. Options are used both by speculators and hedgers, because of their ability to precisely define a risk-return profile fitting the needs of investors. Thus, investigating options returns should offer the possibility of highlighting the risks priced by the markets.

After having been neglected for many years, option returns are now gaining a growing interest among researchers. As highlighted by Coval and Shumway (2001), this interest has many reasons. Analyzing returns rather than prices allow us to be model independent. In addition, returns have an intuitive economic interpretation, as they represent gains or losses on purchased assets, and market operators are generally familiar with return-based measures. Finally, by examining returns, we can consider very specific risks by using different options strategies.

Option returns studies first considered index options. Coval and Shumway (2001) were the first to empirically analyze index option returns in the general context of asset pricing theory. They found that zero beta straddles produce abnormal losses of 3\% per week, and suggest that some other risk, like stochastic volatility risk, may be priced by option returns. The "overpriced puts puzzle" on S\&P500 options, for instance, is well documented on the literature and models relying on one factor (the market return) are usually rejected (Bondarenko, 2003). Jones (2006) tested additional sources of risk, such as volatility and jump risk, to explain this puzzle on S\&P500 options. $\mathrm{He}$ found that the addition of these risk factors reduces the options mispricing but are insufficient to explain the abnormal options returns. Broadie and al. (2009) tried to understand S\&P500 index options returns by using those generated by option pricing models and find that put returns are not as puzzling as they seem at a first glance, and can be explained by jump risk premiums and estimation risk.

More recently, some studies considered equity options. Wilkens (2007) used the framework developed in Coval and Shumway (2001) to study equity option returns. Again, they found that options returns exhibit inconsistencies even with very general propositions of asset-pricing theory. Goyal and Saretto (2009) also study equity option returns and found abnormal returns on volatility portfolios that are not related to obvious sources of risk. 
To the best of our knowledge, foreign exchange option returns have not been specifically studied yet. The aim of this research is to fill this gap, by studying the returns of foreign exchange options, in order to assess if there are any abnormal returns, and if any to find the risk factors that can explain these returns.

Rather than studying single options returns, we want to set up profitable trading strategies using options. The use of options based strategies allow us to isolate specific determinants of options prices in order to precisely identify the nature and origin of the mispricing. To this end, and since options trading rely first on a specific view of the investor about future realizations of the underlying price and volatility, the trading strategy would be based on a signal about one of these parameters. From the point of view of a trader, a profitable trade is linked to the fact that the market is overall wrong about future realizations. For options, this is interpreted as the market expectation of future volatility, implied by the option price, is somehow not correct. So volatility misestimating, more than any model misspecification, is the most obvious source of option mispricing. Della Corte, Ramadorai and Sarno (2015) also use a signal about volatility, but to set up portfolios of forward contracts on currencies.

Since we would like to exploit volatility misestimating, we will use straddle strategies. These strategies do not have directional exposure to exchange rate, so abnormal returns in this case are more probably caused by a biased estimation of the volatility. To estimate the magnitude of this bias, we will use the framework developed by Goyal and Saretto (2009), based on the deviation of the implied volatility from the historical volatility (without any hypothesis about whether historical volatility is a good or bad estimator). Their argument is that, giving the meanreversion behavior of volatility (see for example Poon and Granger, 2003; Kermiche, 2008), and since implied volatility contains an estimate of future volatility, then the implied volatility should reflect the fact that future volatility will be closer to its long-run average historical volatility than to its current level.

Following this argument, we constitute groups of options according to this deviation (direction and magnitude of the deviation). For each currency pair, the historical volatility is based on daily returns of the exchange rates over the previous year, and the implied volatility is of at-the-money options with one month to maturity. These options have been chosen for their liquidity and come from a database provided by Citibank on over-the-counter traded foreign exchange options. We form portfolios of straddles based on deciles on the difference between historical and implied volatility. Strategies consisting on buying the volatility at its highest distance (decile 10) and selling it at its lowest distance (decile 1), yield to average monthly returns of $14.7 \%$. These results are comparable in magnitude to those of Coval and Shumway (2001), who found weekly returns of 3\% for zero-beta straddles using options on the S\&P500. They are also to be related to the results of Goyal and Saretto (2009), who report monthly returns of 22.7\% for straddles using options on stocks.

In a second step, we look at the risk factors which can explain these returns. In case of large positive returns, the question is whether these returns are compensation for some specific risk or are abnormal returns. For this part of the study, we relied on the asset pricing literature on currencies for the choice of the risk factors. However, we did not find any satisfactory relationship between the aggregate risk factors and the monthly returns from our portfolios. We thus examined the persistence of the deviation of the implied volatility from the historical volatility, and the relationship between these deviations and current event on the underlying exchange rate. If the most important deviations (deciles 1 and 10) are only transitory, and follow extreme event on the underlying, then over-reaction of the investors to these events is a possible explanation to the abnormal returns obtained. This conjecture is based on the growing literature on behavioral finance applied to market options, where it is commonly found that volatility over-react to current event. For instance, Stein (1989) documented the fact that investors overweight the short-term implied volatility in their estimation of the long-term one. Poteshman (2001) finds as well that investors over-react in periods of important variations of the volatility.

The remaining of the article is organized as follows. Section 2 describes the database from Citibank used for our analysis. Section 3 details the main patterns observed and quantify the movements in the implied volatility to determine if these movements may be used for a trading strategy. In section 4, we describe the options portfolios strategies, and the returns obtained from these strategies. We then move on, in section 5 , to the study of these returns by looking at the risk factors that can explain the abnormal returns obtained. We finally conclude in section 6 about the main results obtained, and the areas for further research. 


\section{DATA DESCRIPTION}

Our database consists on all the Over-the-counter transactions on foreign exchange options realized by Citibank, during the period from January 1999 to September 2011, on some selected currency pairs. Even if the database includes transactions back to 1988 , we chose to restrict our analysis to this period so as to be able to include currencies against Euro without having to rely on any proxy for the pre-Euro period. We also chose to work on these specific currencies because the corresponding options are the most actively traded by Citibank during this period, thus assuring that the volatilities do not stay constant for several successive days. In addition, unlike portfolios on spot exchange rates, where cross currencies are excluded because they are considered as redundant, we can include them in options portfolios because they move independently on the volatility market, and thus bring new information that is worth analyzing.

For each day on our sample, we have the at-the-money implied volatility of 30-days to maturity options. This maturity corresponds to the most liquid options. The database also includes the spot exchange rate at the time of the transaction and the corresponding interest rates for that maturity.

Table 1 below provides the list of the currencies studied, along with the descriptive statistics of the 1-month implied volatility of each currency pair.

The data are from Citibank OTC transactions on foreign exchange options. Implied volatilities are those of ATM 1month to maturity options. We compute the descriptive statistics of each currency pair in our sample, for the period from January 1999 to September 2011.

Table 1. Summary statistics

\begin{tabular}{l|c|c|c|c|c}
\hline & Mean & Median & Standard deviation & Min & Max \\
\hline AUD/USD & 12.12 & 11.20 & 4.626 & 6.00 & 48.00 \\
\hline USD/CAD & 8.99 & 8.20 & 3.525 & 4.70 & 27.00 \\
\hline USD/CHF & 10.85 & 10.65 & 2.395 & 5.12 & 25.25 \\
\hline EUR/USD & 10.65 & 10.25 & 3.054 & 4.65 & 28.25 \\
\hline GBP/USD & 9.34 & 8.50 & 3.227 & 4.62 & 30.50 \\
\hline USD/JPY & 11.03 & 10.30 & 3.321 & 5.75 & 42.00 \\
\hline EUR/GBP & 8.08 & 7.80 & 3.056 & 3.50 & 23.18 \\
\hline EUR/JPY & 12.17 & 11.40 & 4.810 & 4.80 & 48.18 \\
\hline
\end{tabular}

As we can see from this table, the implied volatilities for these different currency pairs are comparable, both in terms of mean and standard deviation, meaning that a portfolio mixing positions on options on these currencies would be quite homogeneous. The average 1-month implied volatility remains within a range between $8.08 \%$ and $12.17 \%$. The most volatile IV is that of options on EUR/JPY, with a minimum of $4.8 \%$ and a maximum of $48.18 \%$, whereas the less volatile IV is that of options on USD/CHF, with a minimum of $5.12 \%$ and a maximum of $25.25 \%$. 
Figure 1. EUR/USD 1 month ATMF implied volatility

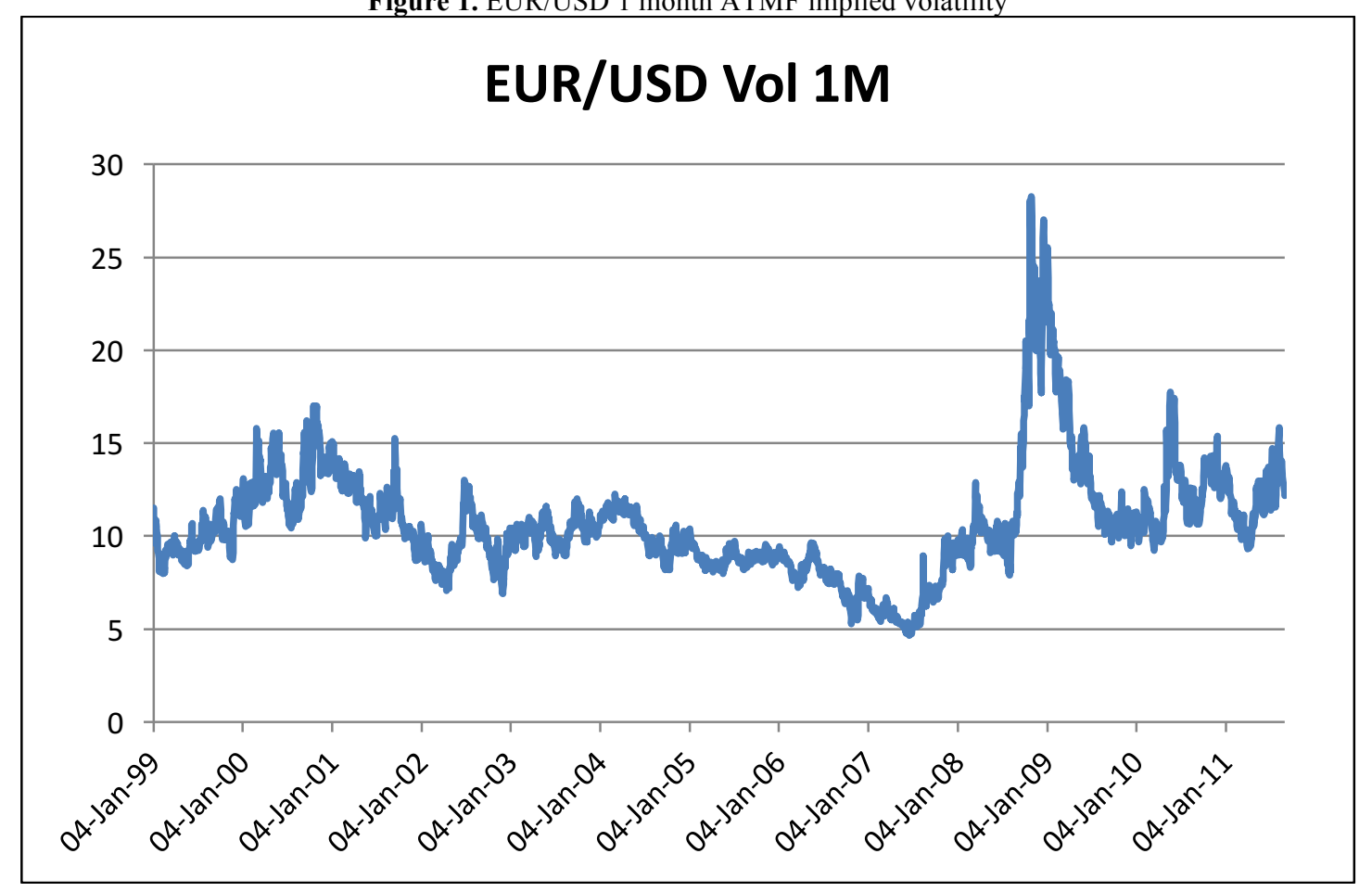

The mean reverting behavior of the volatility have been widely studied and enhanced in the literature (see for example Poon and Granger, 2003; Kermiche, 2008). Figure 1 gives an example of the behavior of the 1-month implied volatility for EUR/USD currency pair during the period of our analysis (January 1999 to September 2011). As we can see, it exhibits a strong mean reverting behavior, globally located around 10\% (the exact mean for this specific serie is $10.65 \%$ from table 1), and regularly disturbed from this region by particular events. The periods of turbulence are characterized by spikes in the implied volatility (a maximum of $28.25 \%$ have been reached during the 2008 financial crisis). The other interesting feature is the asymmetry in the upside and downside movements. Upward movements are more important both in terms of frequence and magnitude than downwards movements. More importantly, the implied volatility returns to its long-run mean more swiftly after a spike up.

The same pattern may be observed for the other currencies. In the next sections, we are going to first try to quantify this behavior, and then see if it is possible to use it as a signal trading to set up options portfolios strategies.

\section{VOLATILITY MOVEMENT'S ANALYSIS}

The first step of our analysis is to examine the movements of the 1-month implied volatility (IV), depending on its distance from the historical volatility (HV). In doing so, we are considering, following Goyal and Saretto (2009) that a large deviation of the implied volatility from the historical one may be indicative of volatility misestimating (or option mispricing). To identify what could be considered as a "large" deviation, we will consider the different deciles of the distance between the implied and historical volatility. In our case, the historical volatility is taken from the previous year daily exchange rates returns; the implied volatility is the 1-month at-the-money volatility provided by Citibank.

At the beginning of each month in our sample, we compute the difference HV-IV for each currency pair, and sort them according to the corresponding decile. We then explore the future variation of the implied volatility at a 1week and 1-month horizon. Table 2 shows the average variation of each decile at the 1-week and 1-month horizon, and the number of times this difference is positive or negative (on percentage) for each horizon. 
As we can see from this table, when the implied volatility is higher than the historical volatility (decile 1 for the largest deviation), the subsequent move will be more often a decrease rather than an increase of the implied volatility, and this is true both at the 1-week and 1-month horizon (the variation is negative in $58.1 \%$ at 1 -week and $59.7 \%$ at 1 -month). We can also see that the average deviation in this case is relatively important at $-0.228 \%$. The same remarks hold for the observations from decile 2 to 5 , at least at the 1-month horizon, but the average deviation and the frequency of negative deviation are less important.

If we consider the other end of the table, representing the most important deviation on the other direction, where the implied volatility is lower than the historical volatility (decile 10), we observe the opposite behavior. The subsequent move is more often an increase rather than a decrease of the implied volatility $(51.1 \%$ for the 1 -week horizon and $53.1 \%$ for the 1 -month horizon). The average move at the 1 -month horizon is $0.199 \%$. These numbers are less impressive than the ones observed when the implied volatility is higher than the historical volatility. This is consistent with the previous sections observation of the implied volatility pattern, characterized by large upward spikes.

We sort currency options in 10 deciles according to the difference between historical and implied volatility. Historical volatility is computed using daily returns over the previous year (annualized). Implied volatility is from Citibank database. Decile 1 represents options with the lowest (negative) difference and decile 10 represents options with highest (positive) difference. Average move size represents the average variation in the implied volatility after 1 week and 1 month, for options initially in deciles 1 to 10 . We also compute the number of times (presented as \%) the subsequent move is positive or negative after 1 week and 1 month for each decile.

Table 2. Volatility movements

\begin{tabular}{|c|c|c|c|c|c|c|c|c|}
\hline \multirow{2}{*}{ Decile } & \multicolumn{2}{|c|}{ Average move size } & \multicolumn{3}{|c|}{ \% times 1-week moves are } & \multicolumn{3}{|c|}{ \% times 1-month moves are } \\
\hline & 1-week & 1-month & $>0$ & $<0$ & $=\mathbf{0}$ & $>0$ & $<0$ & $=\mathbf{0}$ \\
\hline 1 & -0.112 & -0.228 & $38.9 \%$ & $58.1 \%$ & $3.0 \%$ & $38.6 \%$ & $59.7 \%$ & $1.7 \%$ \\
\hline 2 & -0.074 & -0.159 & $42.2 \%$ & $54.7 \%$ & $3.1 \%$ & $42.0 \%$ & $56.4 \%$ & $1.5 \%$ \\
\hline 3 & 0.021 & -0.039 & $45.1 \%$ & $50.7 \%$ & $4.3 \%$ & $42.1 \%$ & $56.2 \%$ & $1.8 \%$ \\
\hline 4 & -0.023 & -0.026 & $42.9 \%$ & $54.0 \%$ & $3.1 \%$ & $41.3 \%$ & $57.0 \%$ & $1.7 \%$ \\
\hline 5 & 0.003 & -0.018 & $43.7 \%$ & $51.8 \%$ & $4.5 \%$ & $41.9 \%$ & $56.0 \%$ & $2.2 \%$ \\
\hline 6 & 0.017 & 0.063 & $45.1 \%$ & $51.6 \%$ & $3.3 \%$ & $44.8 \%$ & $53.3 \%$ & $1.8 \%$ \\
\hline 7 & 0.067 & 0.192 & $46.8 \%$ & $48.7 \%$ & $4.4 \%$ & $46.8 \%$ & $51.2 \%$ & $2.0 \%$ \\
\hline 8 & 0.031 & 0.135 & $46.2 \%$ & $49.8 \%$ & $3.9 \%$ & $45.4 \%$ & $52.0 \%$ & $2.6 \%$ \\
\hline 9 & 0.001 & 0.071 & $44.9 \%$ & $50.7 \%$ & $4.4 \%$ & $45.2 \%$ & $52.5 \%$ & $2.3 \%$ \\
\hline 10 & 0.093 & 0.199 & $51.1 \%$ & $45.2 \%$ & $3.7 \%$ & $53.1 \%$ & $45.0 \%$ & $1.9 \%$ \\
\hline
\end{tabular}

Following these observations, we will examine in the next section, different options strategies by forming portfolios based on the deciles representing the difference between the historical volatility and the implied volatility. We will more specifically focus on the largest deviations, represented by the highest and lowest deciles.

\section{OPTION PORTFOLIO STRATEGIES}

Our aim is to explore the misestimating of the volatility parameter. To this end, we choose to form portfolios that are independent of the underlying fluctuations, and only sensitive to volatility fluctuations. The simplest way to achieve this kind of portfolio using plain vanilla options is to form straddle strategies.

At the beginning of each month, we sort our currency pairs according to the difference between the historical and implied volatility in ten deciles. The lowest decile represents the highest negative difference in volatility and the highest decile represents the highest positive difference. We then form portfolios of straddles by combining a long position in an at-the-money call and an at-the-money put on a given currency pair, with one month to maturity. This is done for each decile. Some deciles may contain several currency pairs, whereas others may contain none for a given month. Our position is held until the end of the month, and the final return is then computed using the exchange rate at that final date. Held-to-expiration call and put returns are defined respectively as: 


$$
\begin{aligned}
& r_{t, T}^{\text {Call }}=\frac{\left(S_{t+T}-K\right)^{+}}{C_{t, T}\left(S_{t}, K\right)}-1 \\
& r_{t, T}^{\text {Put }}=\frac{\left(K-S_{t+T}\right)^{+}}{P_{t, T}\left(S_{t}, K\right)}-1
\end{aligned}
$$

Where $\mathrm{C}_{\mathrm{t}, \mathrm{T}}\left(\mathrm{S}_{\mathrm{t}}, \mathrm{K}\right)$ and $\mathrm{P}_{\mathrm{t}, \mathrm{T}}\left(\mathrm{S}_{\mathrm{t}}, \mathrm{K}\right)$ are respectively the prices at time $\mathrm{t}$ of a call and put option on St, maturing at time $\mathrm{T}$, and with an exercise price $\mathrm{K}$. Even if our database contains daily data, we choose to form our portfolios only once a month and hold them until maturity to avoid any overlapping problems. In addition, and as emphasized by Broadie and al. (2009), monthly options returns both reduce the transactions costs (usually very high for options) and avoid the theoretical and statistical issues generated by high-frequency options returns (see Broadie and al, section 2, for a detailed discussion). This makes monthly returns a popular object of analysis for both academics and practitioners.

The average returns for the three lowest and highest deciles are presented in table 3 , as well as the standard deviations and the Sharpe ratio. We also present in this table the results from a long-short position, which we constitute by buying straddles using options from decile 10 and selling straddles using options from decile 1 .

We form straddle portfolios using options sorted according to the difference HV-IV. One portfolio for each decile is constituted at the beginning of each month in our sample and held until maturity. 10-1 represents a long-short position in straddles from deciles 10 and 1 . We present the mean and standard deviation of the monthly returns and the Sharpe ratio of the portfolio.

Table 3. Portfolios returns

\begin{tabular}{l|c|c|c|c|c|c|c}
\hline Decile portfolios & $\mathbf{1}$ & $\mathbf{2}$ & $\mathbf{3}$ & $\mathbf{8}$ & $\mathbf{9}$ & $\mathbf{1 0}$ & $\mathbf{1 0 - 1}$ \\
\hline Mean & $-10.29 \%$ & $-7.03 \%$ & $-4.55 \%$ & $1.00 \%$ & $6.35 \%$ & $4.37 \%$ & $14.66 \%$ \\
\hline Standard deviation & 0.753 & 0.667 & 0.720 & 0.773 & 0.783 & 0.642 & 0.697 \\
\hline Sarpe Ratio & -0.139 & -0.108 & -0.066 & 0.010 & 0.079 & 0.065 & 0.207 \\
\hline
\end{tabular}

For the lowest deciles, since we are expecting the volatility to decrease, buying a straddle (which is a way to buy the volatility) naturally leads to a negative return. As expected, the lowest return is achieved for the decile 1, corresponding to the spikes in the volatility, and hence to the greatest subsequent downward move. For deciles 2 and 3 , the average return is still negative and increases monotonically. As compared to related literature, the monthly average return of $-10.29 \%$ is in line with the monthly average return of $-12.8 \%$ of Goyal and Saretto (2009) using options on stocks.

Surprisingly, the highest return is not achieved for the decile 10, but for decile 9. However, the average return for decile 10 is still important, with a value of $4.37 \%$, even if not as important as the negative return of decile 1 . Again, this is comparable in terms of scale to the monthly returns of $9.9 \%$ obtained by Goyal and Saretto. This result is also consistent with the idea that the deviations of the volatility from its "average level" are more often upward movements rather downwards movements, and the magnitude of this deviations is also more important in case of upwards movements.

We also obtain an important average monthly return of $14.66 \%$ from our spread portfolio using options from deciles 10 and 1 . In the next section, we will try to relate this return to aggregate sources of risk.

\section{RISK FACTORS}

From the previous section, we found that large returns may be achieved by sorting portfolios according to the distance of the implied volatility from the historical one. More specifically, forming our portfolios by buying straddles using currency options in the highest decile and simultaneously selling straddles using currency options in the lowest (portfolio 10-1) will lead to large positive returns. The question is whether these returns are abnormal returns, or systematic compensation for risk. Since we cannot rely on any formal theoretical framework for currency options returns, we will use, as in related studies on indexes or stock options returns (see for example Coval and Shumway, 2001; Goyal and Saretto, 2009), the corresponding framework for the underlying asset. Indeed, since 
options are derivatives securities, we can reasonably consider that options returns will at least depends on the same risk factors as the underlying returns.

In the asset pricing literature on currencies, factors are derived from currency returns. For instance, following Fama and French (1993), Lustig, Roussanov and Verdelhan (2011) build equally weighted portfolios of currencies sorted according to their forward premium against the US dollar. Then they create two risk factors: RX which is the average excess return of all the portfolios and HML-FX which is an equally weighted portfolio of carry trade positions. Using the traditional Fama-McBeth procedure, they find both candidate factors as being statistically significant in justifying the returns to the currencies once they are sorted according to their discount (carry trade). These results are confirmed by Burnside (2011), Menkhoff, Sarno, Schmeling and Schrimpf (2012) and Dupuy (2013).

Also, the literature considers global equity market volatility as a common risk factor. As mentioned in Brunnermeir, Nagel, Pedersen (2008), prior research has shown that the VIX index is useful in pricing equity markets and other, seemingly unrelated, markets. Using the VIX, Brunnermeir, Nagel, Pedersen (2008), Clarida, Davis, Pedersen (2009) and Christiansen, Ranaldo, Soderlind (2011) find a significant relationship between volatility and the returns to currencies. In the same way, Lustig, Roussanov and Verdelhan (2011) use an indicator which is the average volatility of stock returns in local currency across all currencies in the sample. They show that high interest rate countries tend to offer low returns when equity volatility increases. On the contrary, low interest rate countries offer high returns when volatility goes up. However, using a similar proxy for volatility, Burnside (2011) finds no relationship between the volatility of stock markets and the returns to the carry trade. Also, Lustig, Roussanov and Verdelhan (2011) find that the volatility factor cannot replace HML-FX: in a horse race, HML-FX drives out innovations to the volatility factor. Building on these results, Menkhoff, Sarno, Schmeling and Schrimpf (2011) find that a factor that measures global currency volatility better price carry trade returns especially when combined with RX. This result is confirmed by Christiansen, Ranaldo, Soderlind (2011) who find more reliable results with a global measure of currency volatility instead of the VIX.

In this paper, we propose to renew the tests on factors by combining the methodologies used in the literature on the currency market and on the option market. Building on these literatures, we look whether the asset pricing theory applies to the currency options returns. Especially, we look for a linear relationship between the factors used in the currency literature such as DOL, HML-FX and VIX and the returns to the currency options sorted, as inspired by the option literature, on the difference between historical and implied volatility.

Thus, to achieve our task, we regress the returns of our spread portfolios of straddles (10-1) on the previously defined risk factors:

$$
R_{t}=\alpha+\beta_{D O L} D O L_{t}+\beta_{H M L} H M L_{t}+\beta_{V I X} V I X_{t}+\varepsilon_{t}
$$

Where R is the return of our portfolio, DOL is a dollar risk factor equivalent to RX for Lustig and al. (2001) that is the average excess returns to the positions in all currencies against the USD, HML is a return of a carry trade strategy, and VIX is a volatility index. Although a linear model may seem unlikely to explain option returns, our aim by running this factor-model regression is to see if the options returns used in this analysis may be related in an obvious way to widely accepted sources of risk.

Long-short straddle portfolio returns using options from deciles 10 and 1 (buying straddles from decile 10 and selling straddles from decile 1) are regressed according to the factor-model:

$$
R_{t}=\alpha+\beta_{D O L} D O L_{t}+\beta_{H M L} H M L_{t}+\beta_{V I X} V I X_{t}+\varepsilon_{t}
$$

DOL is a dollar risk-factor, HML is a return from a carry trade strategy, VIX is a volatility index. 
Table 4. Risk-factor model for option returns

\begin{tabular}{c|c|c|c|c|c}
\hline & alpha & DOL & HML & VIX & $\mathbf{R}^{2}$ \\
\hline \multirow{2}{*}{$(1)$} & $0.129^{*}$ & $4.94^{*}$ & -3.09 & & 0.020 \\
& $(1.83)$ & $(1.72)$ & $(-0.63)$ & & 0.023 \\
\hline \multirow{2}{*}{$(2)$} & 0.234 & $5.044^{*}$ & -3.128 & -0.004 & $(-0.62)$ \\
\hline
\end{tabular}

The results from this regression are presented in table 4, first without the VIX as a risk factor, and then by including it. As we can see, the DOL factor is the only significant risk factor in both regressions. Other factors are statistically insignificant to explain returns from our portfolio. The addition of a volatility risk factor only slightly improves the regression, but is insignificant as well. This means that standard linear models cannot explain returns from the longshort straddle strategy used here. These results are comparable to those of other studies trying to use the standard asset pricing framework to explain options returns, as Goyal and Saretto (2009) with stock options.

Since the returns obtained from our portfolios are not related in an obvious way to standard risk factors, two other possibilities remain. Either other risk factors should be considered, and possibly on a non-linear factor-model, or these returns are not compensation for some sources of risk and are rather abnormal. To further explore this possibility, we study the pattern of the difference between historical and implied volatility in the months where the portfolios are constituted. In figure 2, this pattern is illustrated for the EUR/USD currency. Other currencies exhibit the same pattern. The most striking and most interesting feature for us is that important values of the difference, both negative and positive (deciles 1 and 10) are only temporary. We can also note that these extreme values are linked with extreme events on the foreign exchange market as well.

Figure 2. Difference of historical volatility (HV) and implied volatility (IV) for EUR/USD 1-month options

\section{EUR/USD (HV - IV) 1M}

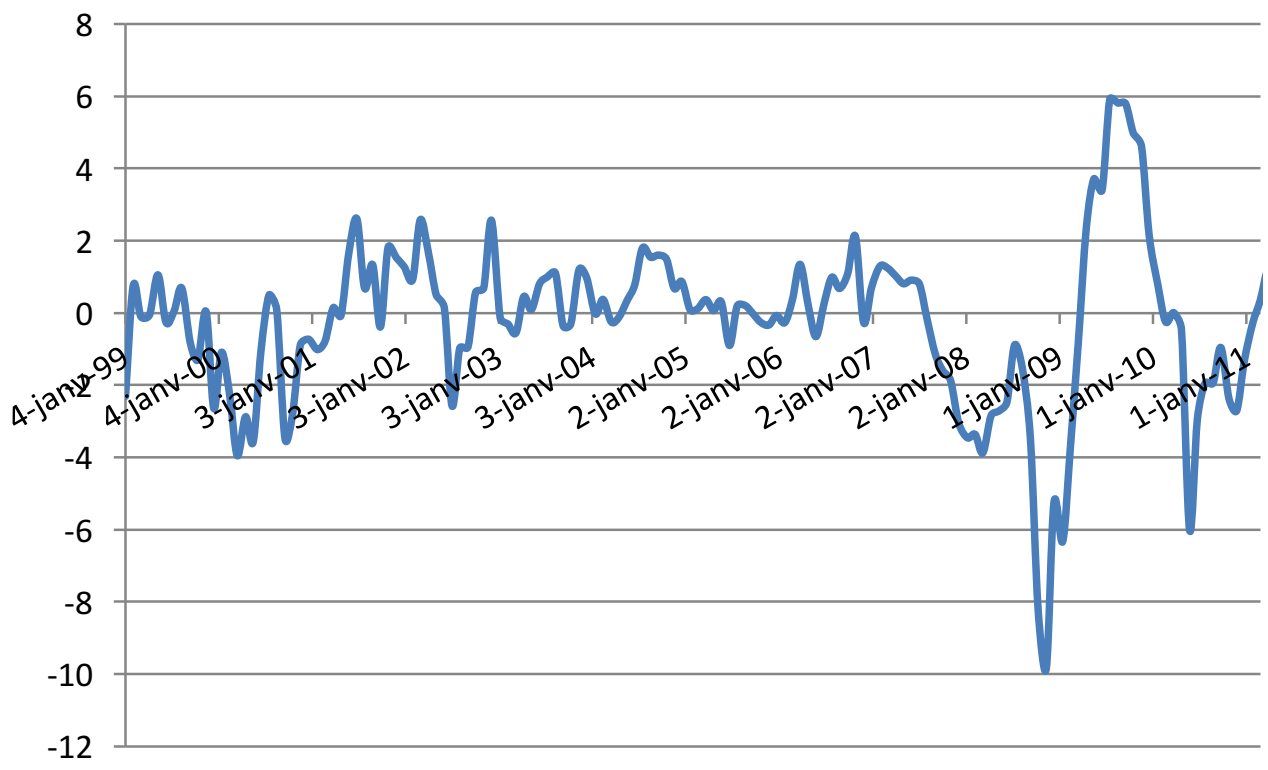

If these returns are abnormal, then they may be related to over or under-reactions of investors to the market. While over and under-reactions are not accounted for in the traditional paradigm of rational agents, the recently growing literature on behavioral finance tends to corroborate this finding. Barberis and al. (1998) enhance the fact that investors initially under-react to the arrival of new information (conservatism bias), before over-reacting in case of persistence of the information (representativeness bias). More recently, Cao and al. (2005) argue that the options market may as well present this kind of inappropriate reactions. Stein (1989) finds that two-months options 
volatilities over-react to shocks on one-month options volatilities, which he interprets as investors overweighting the short term implied volatility in their estimate of the long-term one, rather than considering the mean-reversion pattern in implied volatility. Poteshman (2001) finds as well that investors over-react in periods of important variations of the volatility, which corresponds in our data to the deciles 1 and 10.

In a similar study on stock options returns, Goyal and Saretto (2009) also find abnormal returns that they were unable to relate to any source of risk. Conversely, they relate their finding to the Barberis and Huang (2001) model which departs from the standard rational agents models. In the Barberis and Huang model, investors consider that a stock is less risky than before if it performs well (they are less concerned about losses after a good performance), and riskier if it performs poorly (they become more sensitive to the possibility of additional losses). Goyal and Saretto (2009) find that the departure of the implied volatility from the historical one is only temporary, both in case of a negative and positive difference between the two volatilities (deciles 1 and 10), and that this departure is linked to extreme returns on the underlying. They thus explain the abnormal returns on their options strategies by overreactions of investors acting as in the Barberis and Huang model.

We, as the authors of previous studies, acknowledge the fact that our abnormal returns may be explained by a general formal theoretical model for options returns that is still to be found, but this model will certainly have to take into account the over-reactions of investors in the options market that are highlighted by many authors.

\section{CONCLUSION}

Despite the great interest among researchers and practitioners for option pricing and hedging, it's only recently that options returns started gaining interest among these communities. According to the asset pricing theory, options should reward the owners for the risks they are bearing, as all other risky assets. It's the aim of this paper to test if the option market, and more specifically the foreign exchange option market, respects the standard asset pricing principles.

In this study, we documented the existence of abnormal returns, and thus profitable trading strategies on foreign exchange options. These strategies are obtained by sorting our currency pairs according to a simple criterion based on the distance of the implied volatility from the historical volatility. Based on this criterion, we formed straddle portfolios with options having the lowest (negative) and highest (positive) difference, and obtained monthly average returns of $-10.29 \%$ for portfolios with options on decile 1 , and $4.37 \%$ for portfolios with options on decile 10 .

We then examined whether the options returns for a long-short strategy (buying straddles for options in decile 10 and selling straddles for options in decile 1) are related to aggregate sources of risk. We found that, while the overall level of interest rates is significantly related to the returns, other sources of risk do not seem to explain these returns. Our findings are consistent with other studies on index or equity options market.

To explain these returns, two options exist. The first one is the development of a general formal theoretical model for option returns, including other aggregate risk factors that are possibly non-linearly linked. The second rely on the growing literature on behavioral finance. Both are promising avenues for further research.

\section{ACKNOWLEDGEMENT}

A previous version of this paper has been published on Research Gate.

\section{AUTHOR BIOGRAPHIES}

Lamya Kermiche is Associate Professor of Finance at Grenoble Ecole de Management. Her main areas of research are financial markets, derivatives and risk management. She holds a Ph.D. in Finance from Grenoble University and an engineering degree in computer sciences and applied mathematics. Before joining Grenoble Ecole de Management, Lamya worked as a quantitative analyst in several financial institutions. 
Philippe Dupuy is Associate Professor of Finance at Grenoble School of Management. His areas of research include portfolio management, international finance and currency risk management. He is the author of several articles in the Journal of International Money and Finance, Journal of Asset Management and Australian Economic Review among other. He received his $\mathrm{PhD}$ from Dauphine University in Paris. He previously worked as a quantitative analyst and then as a portfolio manager specialized in foreign exchange risk management in international banks for 12 years in London and Paris.

\section{REFERENCES}

Barberis N., A. Shleifer and R. Vishny (1998). A model of investor sentiment. Journal of Financial Economics, Vol. 49, $307-343$. Barberis N. and M. Huang (2001). Mental accounting, loss aversion and individual stock returns. Journal of Finance, Vol. 56, 1247-1292.

Bondarenko 0. (2003). Why are put options so expensive? Working paper, University of Illinois, Chicago.

Broadie M., M. Chernov and M. Johannes (2009). Understanding index options returns. Review of Financial Studies, Vol. 22(11), 4493-4529.

Brunnermeier, M.K., S. Nagel and L.H. Pedersen (2008). Carry Trades and Currency Crashes. NBER Working Papers no. 14473.

Burnside C. (2011). Carry Trades and Risk. NBER Working paper No.17278

Cao C., H. Li and F. Yu (2005). Is investor misreaction economically significant? Evidence from short- and long-term S\&P 500 index options. Journal of Futures Markets, Vol. 25(8), 717-752

Christiansen, C., A. Ranaldo and P. Söderlind (2011). The time-varying systematic risk of carry trade strategies. Journal of Financial and Quantitative Analysis (JFQA), Forthcoming.

Clarida R., J. Davis and N. Pedersen (2009). Currency Carry Trade Regimes: Beyond the Fama Regression. NBER Working Paper No. 15523

Colchester H. and J. James (2006), Systematic strategies for buying and selling FX option volatility. CitiFX QIS Research Papers.

Coval J. and T. Shumway (2001), Expected option returns. Journal of Finance, Vol. 56(3), 983-1009.

Della Corte P., T. Ramadorai and L. Sarno (2015), Volatility risk premia and exchange rate predictability. Journal of Financial Economics, forthcoming.

Dupuy P. (2013). The tail risk premia of the carry trade. Paris AFFI meeting 2013 papers.

Fama E. F. and K. French (1993). Common risk factors in the returns on stocks and bonds. Journal of Financial Economics, Vol. 33(1), 3-56.

Goyal A. and A. Saretto (2009). Cross-section of option returns and volatility. Journal of Financial Economics, Vol. 94(2), 310326.

Jones C. (2006). A nonlinear factor analysis of S\&P 500 index option returns. Journal of Finance, Vol. 61(5), $2325-2363$.

Kermiche L. (2008). Une modélisation de la surface de volatilité implicite par processus à sauts. Finance, Vol. 29(2), 57-101.

Lustig H.N., N. L. Roussanov and A. Verdelhan (2011). Common Risk Factors in Currency Markets. Review of Financial Studies, forthcoming.

Menkhoff, L., Sarno, L., Schmeling, M. and Schrimpf, A., 2012. Carry Trades and Global Foreign Exchange Volatility, Journal of Finance, Vol. 67(2), 681-718, 04.

Poon S.-H. and C. Granger (2003). Forecasting volatility in financial markets: A review. Journal of Economic Literature, Vol. 41(2), 478-539.

Poteshman A. (2001). Underreaction, overreaction, and increasing misreaction to information in the options market. Journal of Finance, Vol. 56, 851-876.

Stein J. (1989). Overreactions in the options market. Journal of Finance, Vol. 44(4), 1011-1023.

Wilkens S. (2007), Option returns versus asset-pricing theory: Evidence from the European option market. Journal of Derivatives and Hedge Funds, Vol. 13(2), 170-176. 